\title{
Parameterization of Ring Current Adiabatic Energization
}

\author{
M. W. Liemohn \\ Atmospheric, Oceanic, and Space Sciences Department, University of Michigan, Ann Arbor, Michigan \\ G. V. Khazanov \\ National Space Science and Technology Center, NASA Marshall Space Flight Center, Huntsville, Alabama
}

\begin{abstract}
An analysis of the factors that parameterize the net adiabatic energy gain in the inner magnetosphere during magnetic storms is presented. A single storm was considered, that of April 17, 2002. Three simulations were conducted with similar boundary conditions but with different electric field descriptions. It is concluded that the best parameter for quantifying the net adiabatic energy gain in the inner magnetosphere during storms is the instantaneous value of the product of the maximum westward electric field at the outer simulation boundary with the nightside plasma sheet density. In addition, these two quantities alone usually produced large correlation coefficients, along with several other magnetospheric quantities. An analysis is given regarding which parameters could be considered useful predictors of the net adiabatic energy gain of the ring current. Long integration times over the parameters lessen the significance of the correlation. This implies the instant response of the ring current to the particle source and convection. Finally, some significant differences exist in the correlation coefficients depending on the electric field description, and these differences are presented and discussed.
\end{abstract}

\section{INTRODUCTION}

Inside the Earth is a dynamo generating a large dipolar magnetic field. This field extends out in to space, creating a bubble, known as the magnetosphere, around the planet. This magnetic cavity is continuously buffeted by the solar wind, a supersonic flow of charged particles (plasma) streaming from the Sun. The solar wind pulls out magnetic field lines from the Sun, known as the interplanetary magnetic field (IMF), and together the solar wind and IMF compress the dayside of the magnetosphere and elongate the backside. This gives the magnetosphere its characteristic ovoid topology. During quiescent solar wind conditions, the dayside magnetopause distance is $\sim 10$ Earth radii $\left(R_{E}\right)$ while the nightside magnetopause can extend $30-100 \mathrm{R}_{\mathrm{E}}$ downtail [e.g., Dungey, 1961; Siscoe, 1966].

Short Title (TK)

Geophysical Monograph 000

Copyright 2004 by the American Geophysical Union ID \#
Occasionally, the Sun emits a blast of plasma and/or magnetic field, either as continuously produced high-speed streams or as transient ejecta [see Tsurutani and Gonzalez, 1997, for a comprehensive review]. These fast flows form a shock wave at their leading edge, piling up the ambient solar wind and IMF into a high-density sheath region. If the flow is directed at the Earth, then the shock, sheath, and stream/ejection will slam into the magnetosphere. This causes what is known as a magnetic storm [e.g., Gonzalez et al., 1994; Rostoker et al., 1997; and references therein].

Magnetic storms result in numerous space weather effects. The most visible is a brightening and expansion of the auroral ovals as energetic electrons and ions cascade into the upper atmosphere [e.g., Akasofu and Chapman, 1961]. Intense ionospheric outflows populate the magnetosphere (along with solar wind inflow) [e.g., Chappell et al., 1987]. Even though the magnetosphere is being squeezed, there is a global depression of the magnetic field around the equator of the Earth, measured by the well-known "disturbance storm time" Dst index [Sugiura and Chapman, 1960]. This is largely the result of the ring current [e.g., Gonzalez et al., 1994]. Parti- 
cles in the magnetotail (specifically, the plasma sheet, a relatively dense blanket of plasma in the equatorial plane) are convected sunward, and during storms they are injected deep into the inner magnetosphere. Here they are adiabatically energized [e.g., Lyons and Williams, 1980; Lee et al., 1982].

For plasma sheet-ring current ions in the $1-100 \mathrm{keV}$ energy range (the particles carrying the bulk of the near-Earth plasma pressure), the gyration and bounce periods are usually much smaller than the characteristic time scales of the dominant physical processes acting on them. However, their drift periods around the Earth are usually much larger than these characteristic time scales. Therefore, it is the first and second adiabatic invariants that are being conserved, which can result in kinetic energy changes for the particles. Inward convection brings the particles into a region of higher $\mathrm{B}$ (magnetic field), and conservation of the first two invariants causes the particle's total kinetic energy to increase. Similarly, outward convection causes de-energization. This form of adiabatic energization is well known, as evidenced by this quote from Alfvén and Fälthammar [1963, p. 62], "A change in B takes place when the charged particle drifts into a region with different field strength. This drift can be produced by an electric field." It is also discussed in many recent reviews of magnetospheric physics, including Wolf [1995] in the widely-used textbook edited by Kivelson and Russell.

In addition to convection, they particles magnetically drift across the field lines, with electrons flowing eastward and ions flowing westward. This creates a net westward current near the Earth known as the ring current. During magnetic storms, it is largely a partial ring, becoming a symmetric ring only in the recovery phase of the storm [e.g., Takahashi et al., 1990; Chen et al., 1993].

The stormtime ring current is a space weather catalyst. Its inflation of the near-Earth magnetic field [e.g., Parker and Stewart, 1967; Tsyganenko et al., 2002] alters the drift paths of the relativistic electrons in the radiation belts, causing increased precipitation into the upper atmosphere and influencing the post-storm development of the belts [e.g., Hudson et al., 1998; Green and Kivelson, 2001]. Its modulation of the near-Earth electric field [e.g., Jaggi and Wolf, 1973; Fok et al., 2001] alters the subauroral ionospheric wind pattern, augmenting low-density troughs and creating high-density plumes at unexpected times and places, which cause errors in GPS signal processing [e.g., Yeh et al., 1991; Foster et al., 2002]. A thorough understanding of the ring current is therefore critical to predicting space weather and mitigating space environment effects on human life here on Earth.

As was found by Liemohn et al. [2002] and Khazanov et al. [2004a], adiabatic acceleration of the ring current is a significant component of the total energy gain (and thus the total inner magnetospheric current). This paper examines the relationship of the net adiabatic energization to several solar wind and magnetospheric parameters. The analysis is based on results from numerical simulations of the stormtime ring current for the April 17, 2002, disturbance. Section 2 provides an overview of the complexity of the inner magnetospheric processes, and places this study into the context of the overall dynamics of near-Earth space. A brief description of the numerical model is provided in section 3. Section 4 is an objective presentation of the results, while section 5 is an analysis of those results. The major findings of the study are summarized in section 6 .

\section{COMPLEXITY OF THE INNER MAGNETOSPHERE}

Figure 1 presents a schematic of the processes and interactions in the inner magnetosphere, as well as the linkages coupling all of these components. The two boxes under consideration in this study are the "Potential E-field" solver and the "Hot Ions," as it is the electric field that radially convects the particles (thus adiabatically energizing them) and it is the hot ions (rather than the electrons) that carry the majority of the plasma pressure in this region. As seen in Figure 1, however, adiabatic energy gain and loss are only parts of a much larger picture. Here we will discuss these other processes to put the adiabatic energization into perspective. For brevity, many of the references given below will be to our own work in these areas. Robust citations of previous studies by others authors are given in the reference lists of the papers cited here.

The plasma sheet is the primary source of particles for the hot electron and ion populations in the inner magnetosphere. The inflow of particles contains both electrons [e.g., Roederer, 1970; Liemohn et al., 1998; Khazanov et al., 1998] and ions [e.g., Wolf et al., 1982; Liemohn et al., 1999]. The flow of these particles is governed by the topology of the near-Earth magnetic and electric fields [e.g., Alfvén and Fälthammar, 1963; Khazanov et al., 2003a]. Through a variety of processes, some of the electrons and ions are pitchangle scattered into the loss cone, where they precipitate into the thermosphere and ionosphere [e.g., Hultqvist et al., 1976; Khazanov et al., 2002]. In their descent through the atmosphere, they ionize and heat the background particles, resulting in changes to the electrical conductance of the subauroral ionosphere [Galand and Richmond, 2001; Khazanov et al., 2003a]. In addition, longitudinal asymmetries in the magnetospheric currents must be closed through fieldaligned currents (FACs) into and out of the ionosphere [e.g., Iijima and Potemra, 1976; Liemohn et al., 2001b]. The 


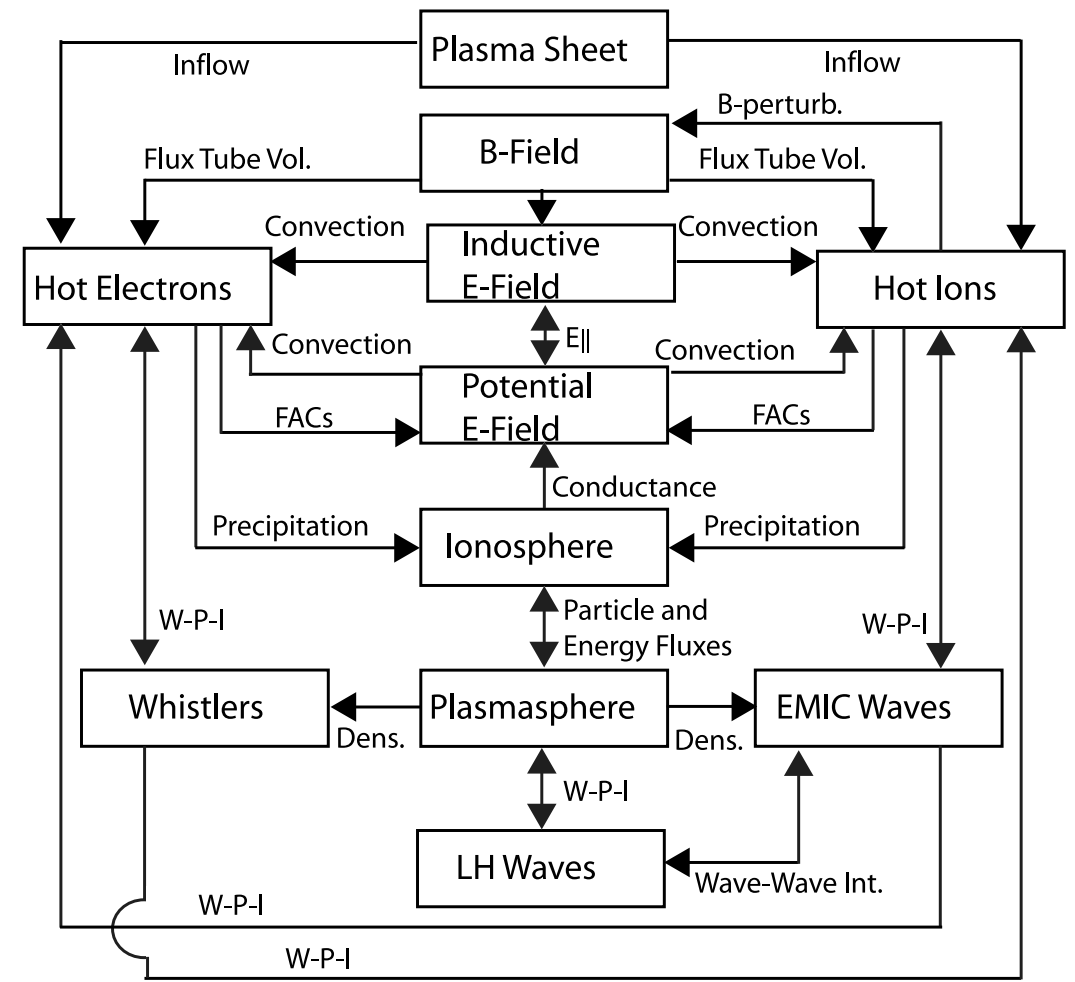

Figure 1. Schematic of the coupling between processes in the inner magnetosphere and subauroral ionosphere.

ionospheric conductance allows perpendicular currents to flow (to connect and balance the FACs), resulting in perpendicular (to the magnetic field lines) electric fields [Goodman, 1995; Amm, 1996; Ridley and Liemohn, 2002]. Assuming the field-aligned conductance to be infinite, the electric fields can be mapped along the field lines to the inner magnetosphere, where they will govern the subsequent flow of the hot electrons and ions. Including this feedback loop in a numerical simulation of the ring current is known as a selfconsistent potential electric field calculation, because the location of the hot particles in the inner magnetosphere modifies the electric fields that determine the locations of the hot particles [e.g., Fok et al., 2001, 2003; Khazanov et al., 2003a; Liemohn et al., 2004]. Of course, the high-latitude electric potential distribution also influences the mid-latitude electric potential pattern, and any self-consistent solution of the subauroral potential must have a high-latitude boundary condition imposed on it.

Many methods have been used to impose a non-self-consistent potential electric field within the inner magnetosphere to convect the stormtime ring current particles [e.g., Fok et al., 1993; Chen et al., 1993; Liemohn et al., 2001a]. The choice of these various fields can lead to large differences in the resulting plasma distributions [e.g., Jordanova et al.,
2001; Khazanov et al., 2003a], including differences in adiabatic energization [Khazanov et al. 2004a, b].

This convective flow is also the major loss of hot particles and energy from the inner magnetosphere. Flowout through the dayside magnetopause has been shown to be the dominant loss mechanism during the main phase of storms, and usually well into the recovery phase [Liemohn et al., 1999, 2001a; Kozyra and Liemohn, 2003]. It is also responsible for the adiabatic de-energization of the particles while they are still close to the Earth [Liemohn et al., 2002].

This central feedback loop between the hot plasma and the potential electric field is influenced by a number of other processes. One such process is the magnetic field perturbation caused by the inner magnetospheric currents [e.g., Parker and Stewart, 1967; Liemohn, 2003]. These perturbations can be large [Tsyganenko et al., 2002], altering the magnetic drift paths of the particles (another feedback loop). In addition, the magnetic field can explosively reconfigure (e.g., substorms), resulting in transient induced electric fields that can influence the particle flow. The induction electric field of substorms, however, has been shown to be a less efficient injection mechanism than the large-scale convective flow [e.g., McPherron, 1997; Wolf et al., 1997; Fok et al., 1999; Liemohn and Kozyra, 2002].

Another factor is the plasmasphere. The plasmasphere is 
the cold, dense particle population in the inner magnetosphere that is slowly filled from the subauroral ionosphere [Lemaire and Gringauz, 1998]. Because this filling process is slow, only those field lines that corotate with the Earth (that is, only those within a few $\mathrm{R}_{\mathrm{E}}$ of the Earth) for several days can become populated with plasmaspheric material [e.g., Carpenter, 1963]. During storms, increased convection strips away the outer plasmasphere, shrinking its size and creating a large drainage plume that extends out to the dayside magnetopause [e.g., Rasmussen et al., 1993]. Several processes occur in the overlap between the hot and cold particles. The first is Coulomb collisions, which cause scattering and energy transfer between the populations [e.g., Fok et al., 1993; Liemohn et al., 2000; Khazanov et al., 2000b]. This energy transfer, particularly that from the hot $\mathrm{O}^{+}$to the cold electrons, is the cause of stable auroral red arcs [Kozyra et al., 1997]. Another is the excitation of plasma waves. With the hot electrons, whistler waves are excited, resulting in plasmaspheric hiss [Liemohn, 1967; Church and Thorne, 1983], which can scatter the hot electrons [Dungey, 1963; Liemohn et al., 1997] and ions [Kozyra et al., 1995]. With the hot ions, electromagnetic ion cyclotron waves are excited [e.g., Kennel and Petschek, 1966; Khazanov et al., 2002, 2003b], which can interact with (i.e., scatter) the hot ions [Jordanova et al., 1997; Khazanov et al., 2002, 2003b] and electrons [Summers and Thorne, 2003]. Given the proper plasmaspheric conditions, these low-frequency EMIC waves can excite lower hybrid waves, which are very efficient at energizing the plasmasphere [e.g., Khazanov et al., 1996b, 1997, 2000a]. This is an additional energy transfer process from the hot particles to the cold plasma via wave-wave interactions. Finally, the plasmasphere can deposit this excess energy (as well as some of its particles) back into the ionosphere, influencing the subauroral conductance.

Another source of hot electrons in the inner magnetosphere is photoionization and impact ionization of the upper thermosphere. Above $\sim 250 \mathrm{~km}$, warm electrons from the ionosphere can escape along the field lines [e.g., Takahashi, 1973; Khazanov and Liemohn, 1995, 2000, 2002]. Some of these electrons are scattered and trapped in the magnetosphere, where they will drift around and eventually redeposit their energy into the ionosphere [e.g., Khazanov et al., 1996a, 1998]. Because these particles can be either long or short lived in the magnetosphere, they are quite efficient at altering the energy deposition pattern into the ionosphere.

It is clear that adiabatic energization is only one component of a complex and interconnected system of processes occurring in the inner magnetosphere and subauroral ionosphere. Large-scale electric and magnetic fields, hot and cold plasma populations, and plasma waves all contribute to the flow of mass, momentum and energy in near-Earth space. In the sections below, we will not attempt to examine the influences of all of these processes on the net adiabatic energy gain of the stormtime ring current. Instead, we will focus on the core feedback loop of the potential electric field with the hot ions. Other processes are included, of course, but are not highlighted as part of this study. However, the reader should keep Figure 1 in mind, realizing that the problem is much larger than just this single interaction.

\section{MATHEMATICAL FORMALISM}

This study uses results from a kinetic ring current-atmosphere interaction model (RAM) that solves the gyration and bounce-averaged Boltzmann equation inside of geosynchronous orbit. See Fok et al. [1993] and Jordanova et al. [1996] for the original development of this code. The present version is described by Liemohn et al. [2004]. It uses secondorder accurate numerical schemes to determine the hot ion phase-space distribution in the inner magnetosphere as a function of time, equatorial plane location, energy, and equatorial pitch angle. Sources are specified by geosynchronous orbit plasma data across the nightside outer boundary, splitting the composition for the $\mathrm{E}<50 \mathrm{keV}$ measurements between $\mathrm{O}^{+}$and $\mathrm{H}^{+}$according to the relations of Young et al. [1982] (higher energy observations are assumed to be $\mathrm{H}^{+}$, minus a $\kappa=5$ high-energy extension to the lower-energy $\mathrm{O}^{+}$distribution). Loss mechanisms include the flow of plasma out the dayside outer boundary, precipitation of particles into the upper atmosphere, pitch angle scattering and drag from Coulomb collisions with the plasmasphere, and charge exchange with the neutral hydrogen geocorona. Coupled to RAM are the plasmaspheric model of Ober et al. [1997] and the geocoronal model of Rairden et al. [1986]. A dipole magnetic field is assumed. This is reasonable in the inner magnetosphere during moderate disturbances. However, it neglects any adiabatic energy gain due to inductive forces during magnetic field reconfigurations (e.g., during substorms), which can influence the near-Earth plasma distribution [Wolf et al., 1997; Fok et al., 1999]. This omission is intentional, because this study focuses on the net adiabatic drift caused by the choice of electric field model.

Three choices for the inner magnetospheric potential electric field will be used. The first option is the modified McIlwain [1986] E5D model (as revised by Liemohn et al. [2001a]), which is an analytical two-cell convection pattern (hereafter the modified McIlwain field). The second option is to map the Weimer [1996] potential distribution into the inner magnetosphere along the dipole magnetic field (hereafter the Weimer-96 field). The third option is a self-consistent electric field description, where the inner magnetospheric electric fields are a consequence of the RAM-generated 
plasma distributions, the ionospheric conductance pattern, and the high-latitude boundary condition (from Weimer-96). Details of the computational scheme for this electric field choice are given by Liemohn et al. [2001b, 2004], Ridley et al. [2001, 2004], and Ridley and Liemohn [2002]. This electric field model is similar to that in other self-consistent inner magnetospheric electric field calculations [Wolf et al., 1982, 1997; Fok et al., 2001; Khazanov et al., 2003a], with the primary difference being the conductance pattern.

The model includes not only drifts in configuration space (from the convection electric field, corotation, and gradientcurvature effects) but also drifts in velocity space. These latter drifts are derived from the conservation of the first and second adiabatic invariants, and result in energization (de-energization) as the particles move inward (outward) across magnetic field isocontours. Thus, it is referred to as adiabatic energization, and it is this net energy gain that will be related to other stormtime parameters in the following section.

\section{RESULTS}

The purpose of this study is to examine the relationship between the net adiabatic energy gain of the ring current ions during a magnetic storm and various "driver" parameters. Before addressing this topic, it is useful to quantitatively show the relationship between the ring current and the Dst index. Because the net current in the inner magnetosphere is westward, the resulting magnetic perturbation at the equator of the Earth is southward (opposite to the dipole field). This is the same direction as the excursion of Dst during storms (negative). Dessler and Parker [1959] and Sckopke [1966] analytically derived a formula relating the total energy content of the ring current to the magnetic perturbation at the center of the Earth, and this relationship has been upheld numerically, with some caveats [e.g., Carovillano and Siscoe, 1973; Liemohn, 2003]. Using the Dessler-ParkerSckopke (DPS) relation, results from models such as RAM can be directly compared against $D s t$ to show the relative contribution to $D s t$ from the ring current. Figure 2 shows such comparisons for two storm events (for details of these magnetic storms, see Liemohn et al. [2001a] and Kozyra et al. [2002]). The agreement between model and data becomes even better when other known contributors to Dst are taken into account, such as induced currents in the Earth, the magnetopause currents, and the cross-magnetotail current. This illustrates that the ring current is a major source of magnetic perturbation in near-Earth space, with societal consequences (as mentioned in section 1). As discussed in several studies [e.g., Lyons and Williams, 1980; Liemohn et al., 2002; Khazanov et al., 2004a], adiabatic energization is a
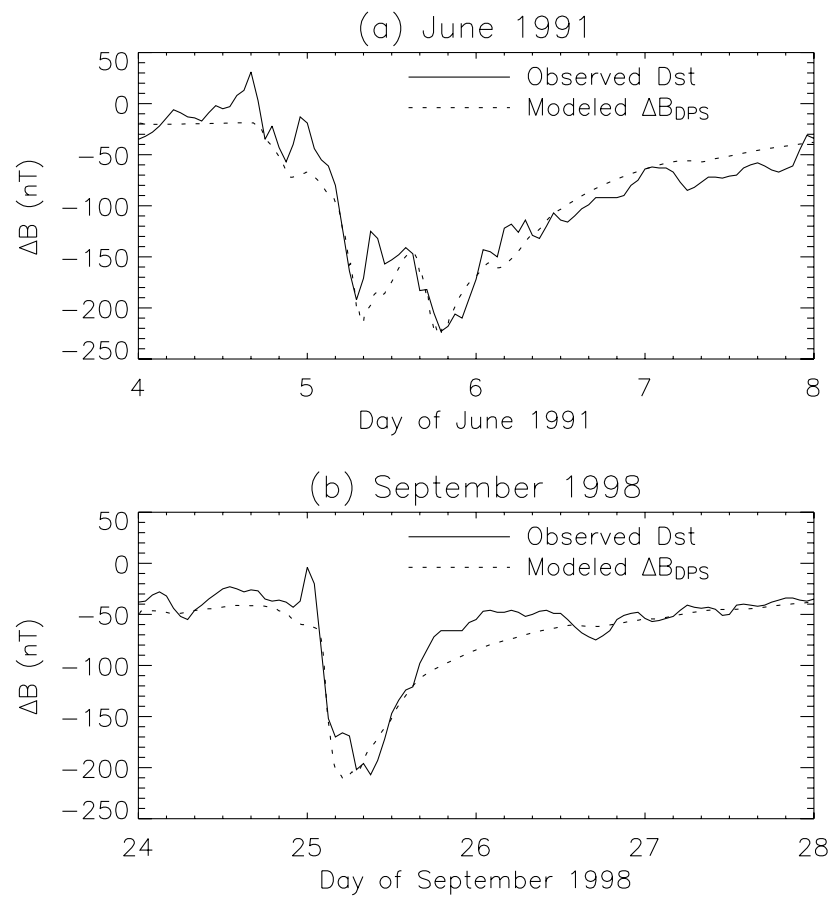

Figure 2. Observed Dst (solid lines) and modeled $\Delta \mathrm{B}_{\mathrm{DPS}}$ (dotted lines) for two magnetic storms, (a) June 4-7, 1991, and (b) September 24-27, 1998.

large contributor to the total energy input to the ring current ions during storms. Thus, an understanding of what controls the net adiabatic energy gain of the ring current is an essential step in understanding near-Earth space.

The storm that occurred on April 17, 2002, is chosen for the computational experiments from which we will examine the adiabatic energization. The study of Liemohn et al. [2004] previously analyzed results from this model for this event. They showed that several electric field options produce different levels of accuracy with respect to the observed plasmapause location (from the EUV instrument on the IMAGE spacecraft). To summarize their results, they found that a self-consistent electric field is better than a Weimer96 electric field, which in turn is better than a modified McIlwain electric field. Liemohn et al. [2004] only briefly discussed the hot ion results from the numerical simulations. In the present study, one aspect of the ring current will be investigated: the net adiabatic energy gain of the hot ions in the inner magnetosphere during the storm. In this section, an objective presentation of the results is given, and these results are interpreted and discussed in section 5 below.

Figure 3 shows various observed and simulated quantities as a function of time for April 17, 2002. Plotted in Figure $3 \mathrm{a}$ is the total ring current energy of the ring current ions inside the simulation domain for the three simulations being considered. The storm occurs during the second half of April 


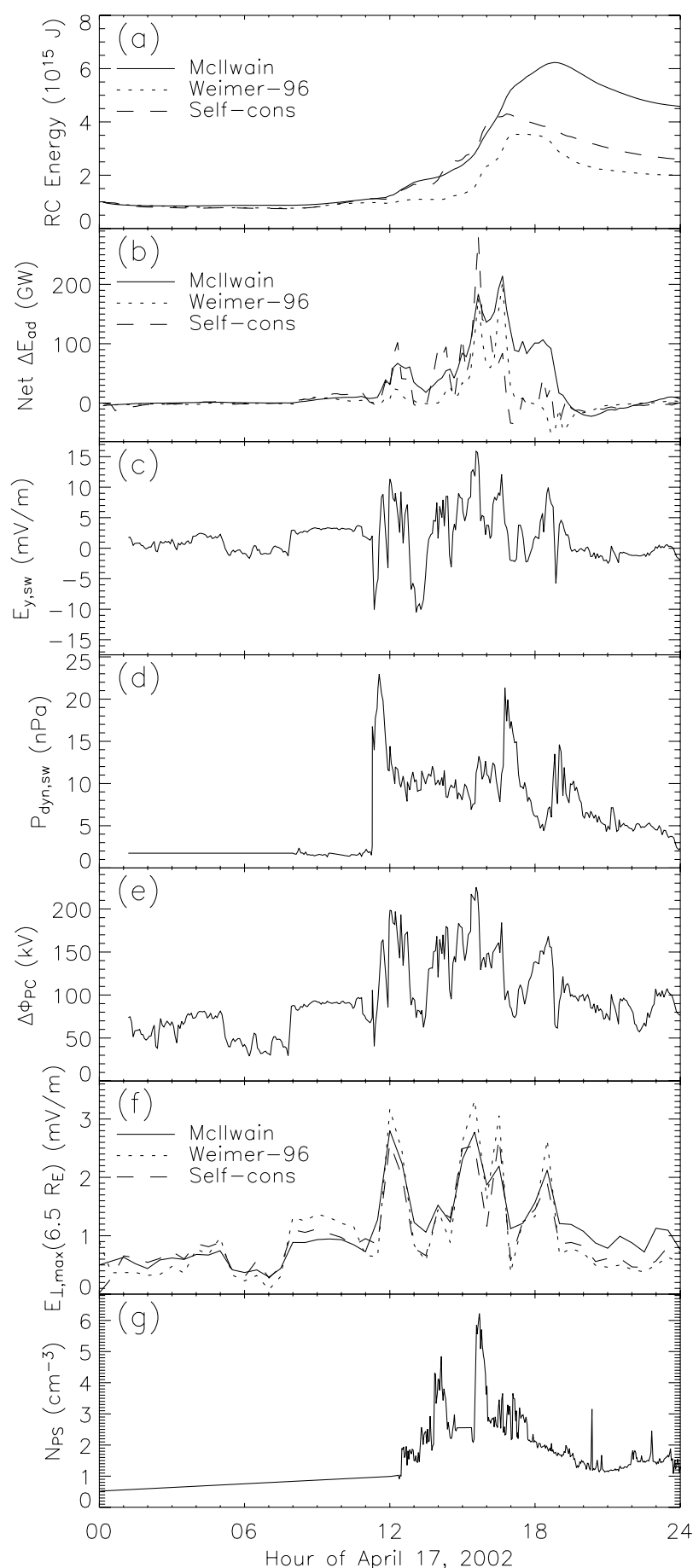

Figure 3. Time series of various simulated and observed quantities during the April 17, 2002, magnetic storm. Shown are (a) total kinetic energy of the simulated ring current for the three electric field descriptions; (b) net adiabatic energy gain from the three runs; (c) solar wind motional electric field; (d) solar wind dynamic pressure; (e) cross polar cap potential difference; (f) maximum westward electric field at $6.5 \mathrm{R}_{\mathrm{E}}$; and $(\mathrm{g})$ nightside plasma sheet density as observed by the LANL MPA instrument.
17, with a main phase lasting about 6 hours and an equally long recovery phase. It is seen that the three potential electric field choices yield distinctly different growth and decay time series, as well as different peak energy content values. Figure $3 \mathrm{~b}$ shows the net energy gain $\Delta \mathrm{E}_{\mathrm{ad}}$ (or loss, if negative) due to adiabatic drifts inside the simulation domain. As with the results in the previous panel, it is seen that the three electric field options produce different time series of adiabatic energy gain, as well as different maximum values.

Solar wind quantities are given in the next two panels. The solar wind motional electric field is presented in Figure $3 \mathrm{c}$ and the solar wind dynamic pressure is plotted in Figure $3 \mathrm{~d}$, both computed from instruments on the ACE satellite. These quantities have been time shifted from the upstream location of ACE (at the L1 point) to Earth by a simple $\mathrm{x}_{\mathrm{GSM}} / \mathrm{v}_{\mathrm{x}, \mathrm{GSM}}$ translation. Both of these quantities are relatively quiet until shortly after 11:00 UT, when the shock hits the magnetosphere. There is a data gap, however, until 8:00 UT in the solar wind plasma observations (straight line segment in Figure 3d). For the rest of the day, ACE observed the passage of the compressed sheath. It should be mentioned that the magnetic cloud (piling up the sheath material) arrived at the Earth early on April 18, causing a subsequent magnet storm on that day. Two more storms occurred over the next week as the same active region on the Sun continued to emit solar flares and coronal mass ejections.

Figure $3 \mathrm{e}$ is the cross polar cap potential from the Weimer96 electric field model. This is the potential difference applied to all of the simulations. The potential jumps quickly up to nearly $200 \mathrm{kV}$, then drops back down near $50 \mathrm{kV}$ during a northward interplanetary magnetic field interval (negative $\mathrm{E}_{\mathrm{y}, \mathrm{sw}}$, as seen in Figure 3c), and then hovers between $150 \mathrm{kV}$ and $200 \mathrm{kV}$ for several hours. It then drops down below $100 \mathrm{kV}$ and, with one exception just before 19:00 UT, remains low for the remainder of the day.

Each electric field option uses the cross polar cap potential difference in Figure $3 \mathrm{e}$ as an overall convection strength parameter, but they use it in different ways. The modified McIlwain model simply uses this quantity as a strength parameter for its analytical potential distribution. The general pattern in the inner magnetosphere is the same at all times, with variations due to this strength parameter and a shielding parameter scaled by Kp. The Weimer-96 model does not really use this potential difference in the inner magnetosphere. It is a statistical spherical harmonic fit to observed ionospheric drifts, and therefore the mid-latitude pattern is related to the total potential difference but does not have to scale with it. Similarly, the self-consistent field model only indirectly uses this quantity. Instead, it applies the Weimer-96 potential from $\sim 72^{\circ}$ magnetic latitude as a 
high-latitude boundary condition in the Poisson solver, and the potential pattern at lower latitudes is highly dependent on the location and intensity of the subauroral ionospheric conductance and field-aligned currents. Therefore, it is useful to consider another electric field quantity. Figure $3 \mathrm{f}$ shows the maximum westward electric field $\mathrm{E}_{\perp \text {,max }}$ (which causes inward radial drifts) at $6.5 \mathrm{R}_{\mathrm{E}}$ (in the outermost ring of grid cells of the simulation). It is seen that the timing and magnitudes of the peaks of $E_{\perp, \max }$ for the three simulations generally follow each other, because of the connection with the cross polar cap potential shown in Figure 3e. There are differences, however, and their impact will be discussed later.

The nightside plasma sheet density $\mathrm{N}_{\mathrm{PS}}$ as observed by the magnetospheric plasma analyzer (MPA) instrument on the Los Alamos National Laboratory (LANL) geosynchronously orbiting spacecraft is shown in Figure 3g. Moments of the observed plasma distribution from $100 \mathrm{eV}$ to $40 \mathrm{keV}$ are included in this time series when the spacecraft is within 4 hours of local midnight. When more than one satellite is in the "nightside" window, the highest moment value was selected for this plot. Note that there is a data gap during the first half of this day (the straight line segment). The flux distributions were used as time-varying boundary conditions for the simulations. Data gaps in the time series are filled in by interpolation from the previous and next valid observations. It is seen that the near-Earth plasma sheet density was elevated above $2 \mathrm{~cm}^{-3}$ throughout the main phase of the storm (compared with $\leq 1 \mathrm{~cm}^{-3}$ during quiet times), with two brief intervals of densities up to 4 and $6 \mathrm{~cm}^{-3}$, respectively.

Figures 4-6 present scatter plots of the net energy gain from adiabatic acceleration and deceleration (the time series shown in Figure $3 \mathrm{~b}$ ) with respect to 10 different parameters. Figure 4 shows the simulation results with the modified McIlwain electric field description, Figure 5 presents results with the Weimer-96 electric field in the model, and Figure 6 contains plots for the run with a self-consistent electric field. The 10 parameters along the $\mathrm{x}$-axis of the 10 panels are, respectively: (a) solar wind motional electric field (from Figure 3c); (b) solar wind dynamic pressure (from Figure 3d); (c) nightside plasma sheet density (from Figure 3g); (d) cross polar cap potential (from Figure 3e); (e) maximum westward electric field at $6.5 \mathrm{R}_{\mathrm{E}}$ (from Figure $3 \mathrm{f}$ ); (f) the average westward electric field around a circle at $6.5 \mathrm{R}_{\mathrm{E}}$ (summed over only those portions of the circle with westward field); (g) the multiplication of the maximum electric field and the nightside plasma sheet density; (h) like (g) but averaged over the previous hour; (i) like (g) but averaged over the previous 2 hours; and (j) like ( $g$ ) but averaged over the previous 4 hours. Listed on each panel is the correlation coefficient. Each point is a ten-minute average of the net energy gain and the parameter. In addition, points are only shown for the 12-hour interval surrounding the storm peak: that is, from 11:00 UT to 23:00 UT on April 17, 2002. This also avoids the gaps in the solar wind and LANL MPA data sets. Listed on each panel is the Pearson correlation coefficient $\left(\mathrm{R}_{\mathrm{P}}\right)$ and the Spearman rank correlation coefficient $\left(\mathrm{R}_{\mathrm{S}}\right)$.

Several features in Figures 4-6 are worth highlighting. The first is the high level of significance for most of the scatter plots. Because there are 72 points on each panel, the 95\% significance level (that the relationship is not random) is $\sim 0.25$. Thus, all of the panels in Figure 4 show statistically significant relationships, and only a few plots in Figures 5 and 6 do not meet these thresholds. The highest correlation coefficients for the modified McIlwain electric field simulation (Figure 4) are found in Figures $4 \mathrm{~g}$, 4h, and $4 \mathrm{i}$, the instantaneous, previous-one-hour, and previous-two-hour averages (respectively) of $\mathrm{E}_{\perp, \max }$ times $\mathrm{N}_{\mathrm{PS}}$. Very high coefficients are also calculated for Figures $4 \mathrm{c}, 4 \mathrm{e}$, and $4 \mathrm{f}$, the MPA density, the maximum westward electric field, and the average westward electric field, respectively. Similarly, for the Weimer-96 field simulation (Figure 5), the high coefficients are found for Figure $5 \mathrm{~g}$ and $5 \mathrm{~h}$. The self-consistent field simulation (Figure 6), the top coefficients are found in Figures $6 \mathrm{~d}$ (cross polar cap potential), 6e, 6f, and 6g. Large correlation coefficients are also calculated for Figure $6 a$, the solar wind motional electric field. The two relationships with coefficients consistently near the bottom of the order are those between $\Delta \mathrm{E}_{\mathrm{ad}}$ and $\mathrm{P}_{\mathrm{dyn}, \mathrm{sw}}$ and $\Delta \mathrm{E}_{\mathrm{ad}}$ and the previous-four-hour average of $\mathrm{E}_{\perp, \max }$ times $\mathrm{N}_{\mathrm{PS}}$.

It should be noted that the points in Figures 4-6 are not completely independent. The plasma takes some time ( hours) to flow through the inner magnetosphere, and so an injection of a blob of plasma in through the outer boundary will result in a sinusoidal time series to $\Delta \mathrm{E}_{\mathrm{ad}}$. The particles will first be convected inward in radial distance, during which they will experience adiabatic energization. On the dayside, however, they will be convected outward and undergo adiabatic deceleration. In steady state, such an injection will eventually be completely lost out the dayside outer boundary and $\Delta \mathrm{E}_{\mathrm{ad}}$ will return to zero. Therefore, the reported statistical significance of the correlation coefficients should be treated as an upper limit, because the degrees of freedom is actually substantially lower than the 72 points in each panel. The historical influence is most pronounced in the last three panels of Figures 4-6. Because each point in the "instantaneous" panel (Figures $4 \mathrm{~g}, 5 \mathrm{~g}$, and $6 \mathrm{~g}$ ) is a 10minute average of the modeled $\Delta \mathrm{E}_{\mathrm{ad}}$ results and the abscissa quantity, the points in the last three panels are running averages over the previous 6,12 , and 24 points. Therefore, the plots resemble hodograms, because each point contains most 

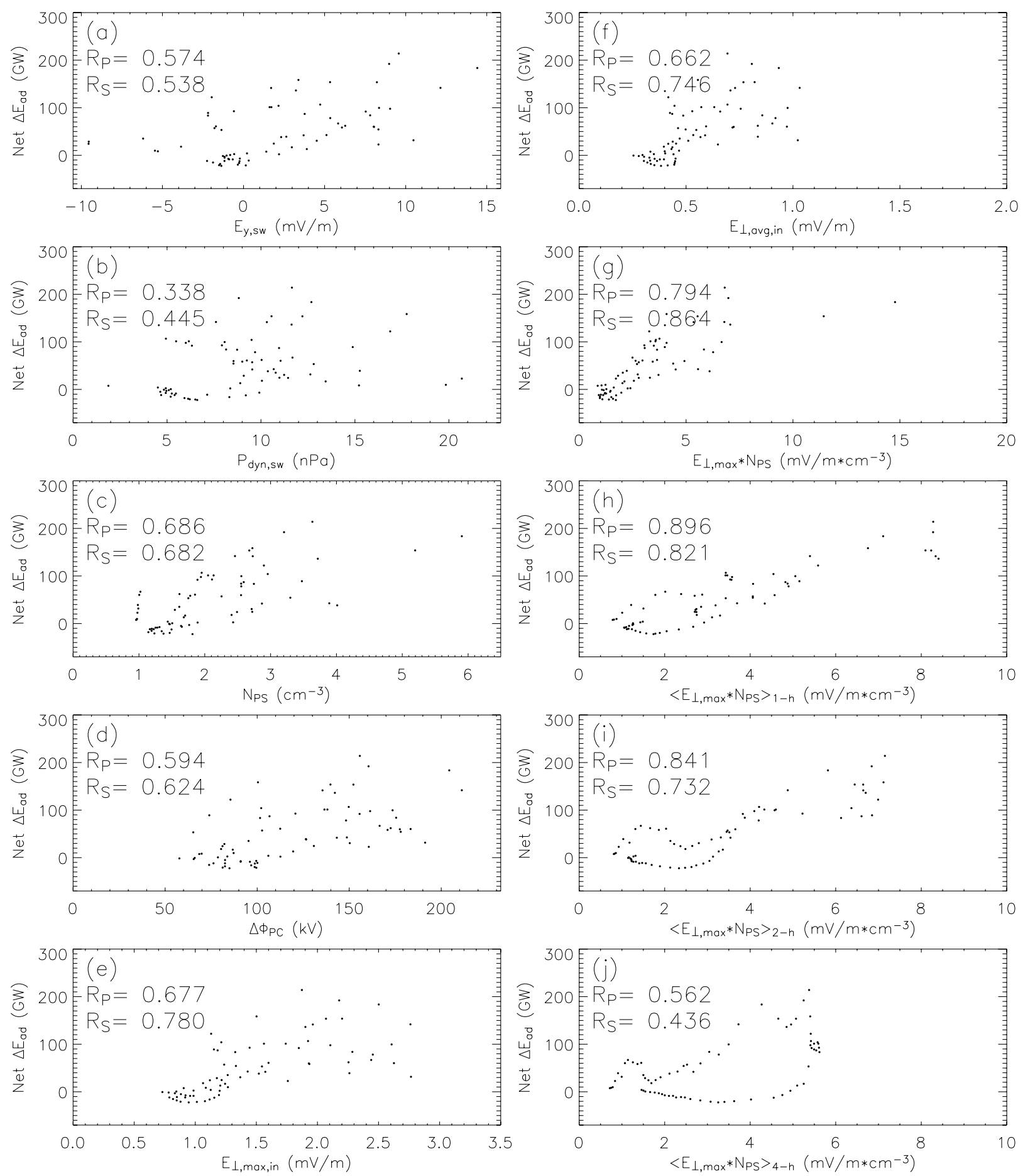

Figure 4. Scatter plots of the net adiabatic energy gain versus various quantities for the simulation using the modified McIlwain electric field model. Listed on each panel is the Pearson correlation coefficient and the Spearman rank correlation coefficient. 

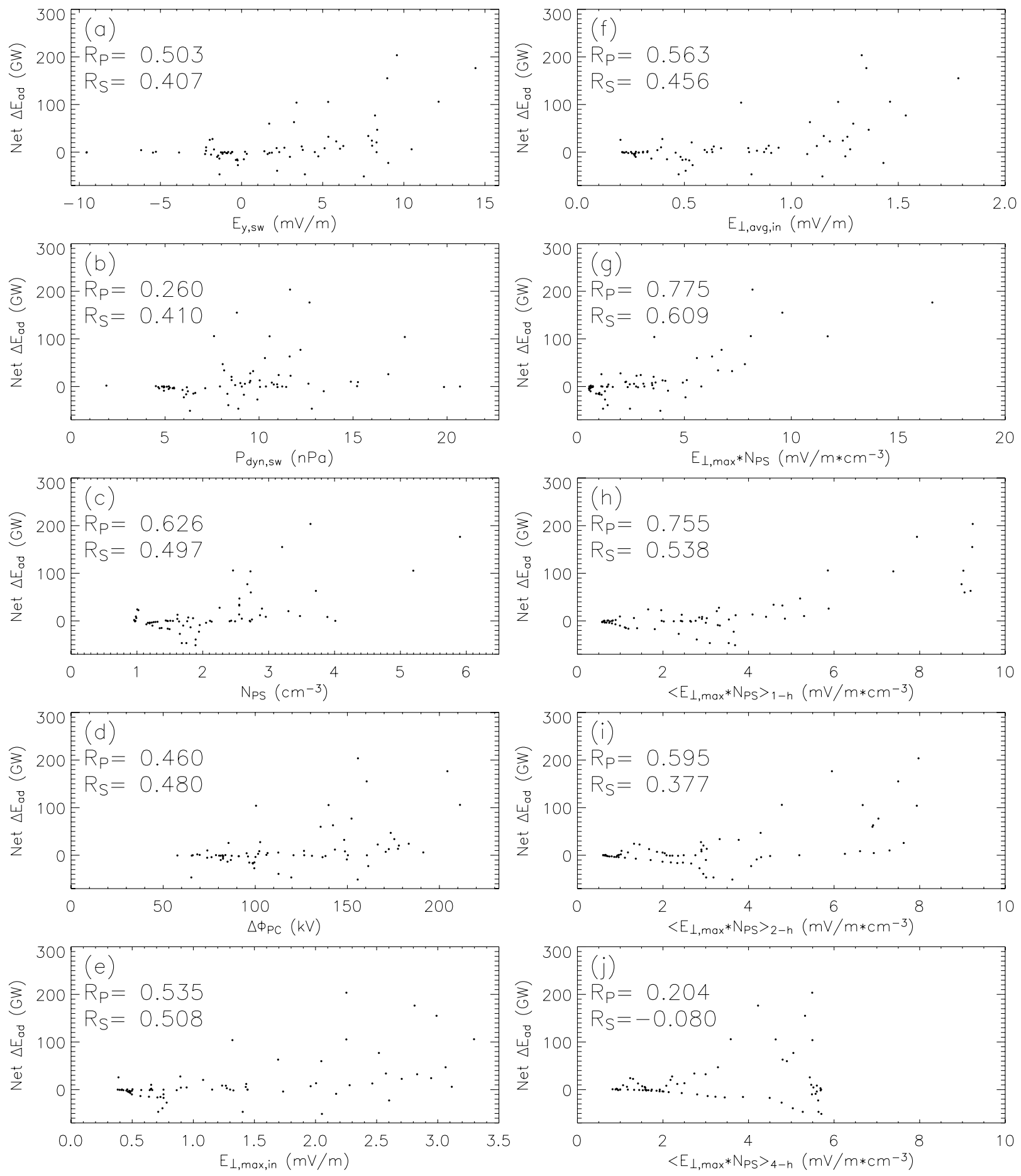

Figure 5. Same as Figure 4 except for the simulation using the Weimer-96 electric field model. 

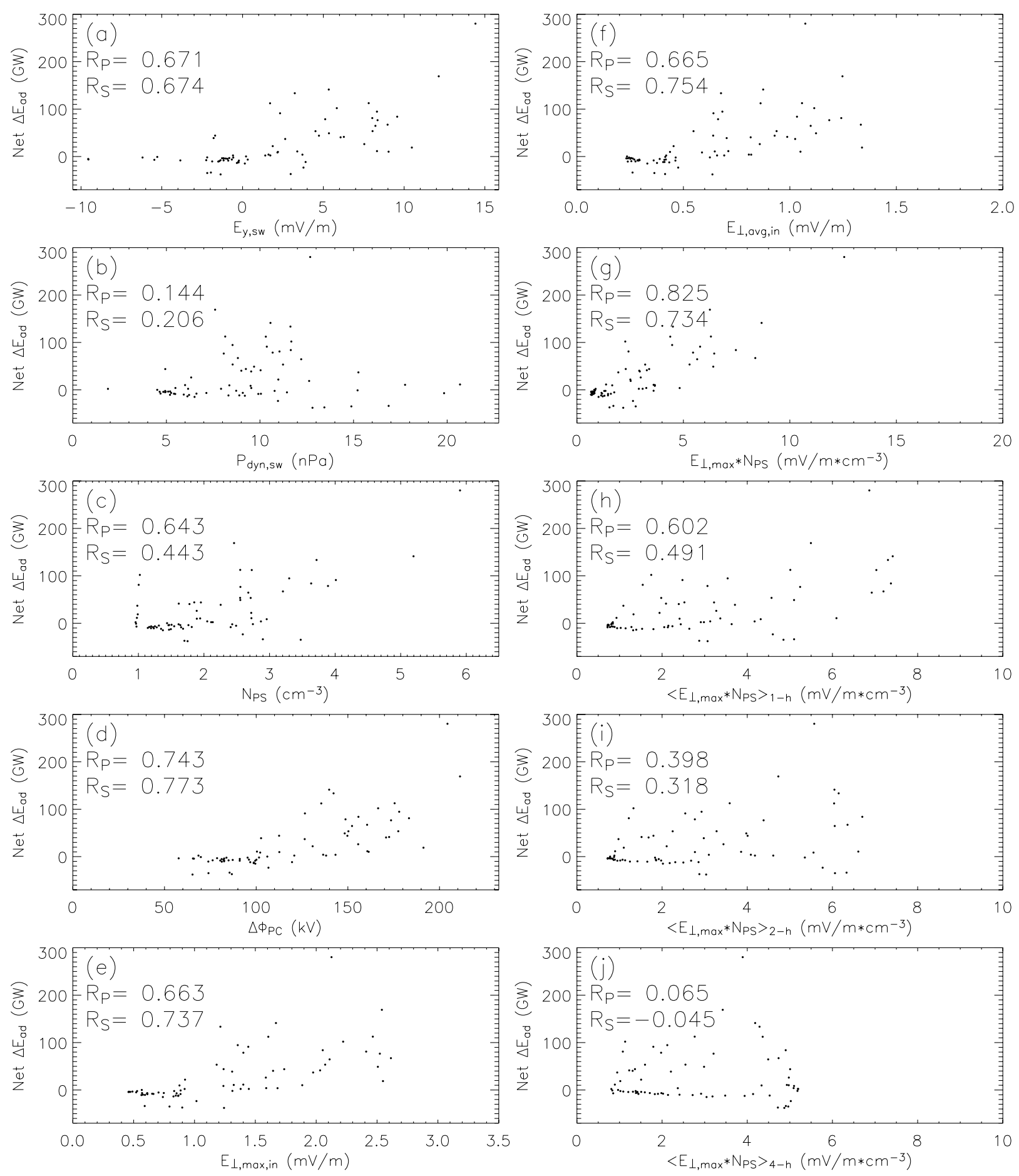

Figure 6. Same as Figure 4 except for the simulation using the self-consistent electric field model. 
of the data used in calculating the previous point. This trait is especially evident in the previous-four-hour average plots in Figures $4 \mathrm{j}, 5 \mathrm{j}$, and $6 \mathrm{j}$.

\section{DISCUSSION}

Let us now interpret the relationships presented in section 4. In particular, the goal of this discussion is to understand the factors influencing the adiabatic energization of ring current particles in the inner magnetosphere.

Because the solar wind and IMF are the source of the free energy in the magnetospheric system, one would expect a relationship between the solar wind parameters and the net adiabatic energy gain. Comparing Figure $3 b$ with Figures $3 \mathrm{c}$ and $3 \mathrm{~d}$, it appears that the net adiabatic energy gain tracks the solar wind quantities. Figures $4 a, 5 a$, and $6 a$ reveal that the statistical significance between $\Delta \mathrm{E}_{\mathrm{ad}}$ and $\mathrm{E}_{\mathrm{y}, \mathrm{sw}}$. The coefficients are usually not the highest among the various correlations considered, though. A strong relation is expected, because many of the Dst prediction algorithms often rely solely on $\mathrm{E}_{\mathrm{y}, \mathrm{sw}}$ [Burton et al., 1975; O'Brien and McPherron, 2000a], and the ring current is a major contributor to the stormtime Dst index. $\mathrm{P}_{\mathrm{dyn}, \mathrm{sw}}$ usually has an even lower correlation coefficient, as seen in Figures 4b, 5b, and $6 b$. For the self-consistent field results (Figure $6 b$ ), both $R_{P}$ and $R_{S}$ are below the $95 \%$ confidence level. The solar wind density $\mathrm{N}_{\mathrm{sw}}$ (not shown) typically has even lower correlation coefficients than $\mathrm{P}_{\text {dyn,sw }}$. There is some debate as to whether $\mathrm{P}_{\text {dyn,sw }}\left(\right.$ or $\mathrm{N}_{\mathrm{sw}}$ ) directly influences the stormtime ring current, with some studies finding a correlation [e.g., Fenrich and Luhmann, 1998; Borovsky et al., 1998; Smith et al., 1999] while others do not [e.g., O'Brien and McPherron, 2000b]. The present study finds a weak correlation at best.

A quantity related to the solar wind parameters is the cross polar cap potential (Figure 3e). The time series of $\Delta \Phi_{\mathrm{PC}}$ is a convolution of that from $\mathrm{E}_{\mathrm{y}, \mathrm{sw}}$ and $\mathrm{P}_{\mathrm{dyn}, \mathrm{sw}}$, as derivatives of these values are included in the expansion coefficients used by the Weimer-96 model. As seen in Figures 4-6, the $\Delta \mathrm{E}_{\mathrm{ad}}-\Delta \Phi_{\mathrm{PC}}$ relationship usually has higher correlation coefficients than either $\mathrm{E}_{\mathrm{y}, \mathrm{sw}}$ or $\mathrm{P}_{\mathrm{dyn}, \mathrm{sw}}$. The significance of this relationship is reasonable because $\Delta \Phi_{\mathrm{PC}}$ is a good measure of the cross tail convection intensity, and therefore it is a good indicator of the rate at which plasma is delivered to (and convected through) the inner magnetosphere.

A more specific quantity to consider is the westward electric field $\mathrm{E}_{\perp}$ on the outer boundary of the simulation domain. Figure $3 \mathrm{f}$ plots the maximum value of this quantity for the three simulations, and the time series closely follow the trends in $\Delta \Phi_{\mathrm{PC}}$. Differences exist among the simulations, though, and so it is useful to consider $\mathrm{E}_{\perp}$ as well as $\Delta \Phi_{\mathrm{PC}}$. In the scatter plots, Figures $4 \mathrm{e}, 5 \mathrm{e}$, and $6 \mathrm{e}$ show the $\Delta \mathrm{E}_{\mathrm{ad}}-$
$\mathrm{E}_{\perp, \max }$ relationship is highly correlative. This is expected because $E_{\perp, \max }$ is a direct measure of the convective flow (and thus the adiabatic energization) in the inner magnetosphere. Similarly, Figures 4f, 5f, and 6f, which show the $\Delta \mathrm{E}_{\mathrm{ad}}-\mathrm{E}_{\perp}, \mathrm{av}$ relationship, also have very high correlation coefficients.

Another factor directly influencing the amount of adiabatic energization in the inner magnetosphere is the amount of plasma being convected into the region. Figure $3 \mathrm{~g}$ shows $\Delta \mathrm{E}_{\mathrm{ad}}$ against these values, and a comparison with the lines in Figure $3 b$ reveal a qualitative match between the time series. Figures $4 c, 5 c$, and $6 c$ show the quantitative relationship between $\Delta E_{a d}$ and $N_{P S}$. The correlations are often large, but typically not as large as those of $\mathrm{E}_{\perp}$. The lower coefficients are most likely because of cumulative effect of $\mathrm{N}_{P S}$ on $\Delta \mathrm{E}_{\mathrm{ad}}$. That is, the particles take some time to drift through the inner magnetosphere, and so a comparison against the instantaneous nightside plasma sheet density may not be the most appropriate choice. In addition, the particles must be inwardly convected by a westward electric field, and so the presence of a dense plasma sheet does not guarantee large amounts of energy gain.

A more suitable parameter with which to compare is the product of $E_{\perp}$ and $N_{P S}$. This is a measure of the energy flux into the system, and therefore should be a good indicator of $\Delta \mathrm{E}_{\mathrm{ad}}$. The scatter plots for $\mathrm{E}_{\perp, \max } * \mathrm{~N}_{\mathrm{PS}}$ are shown in Figures $4 \mathrm{~g}, 5 \mathrm{~g}$, and $6 \mathrm{~g}$, revealing a very high correlation coefficient that is often larger than either $E_{\perp, \max }$ or $\mathrm{N}_{P S}$ alone. It appears that the correct parameter has been found. However, this high correlation is for the product of the instantaneous values. Integrating over some time interval into the past might prove even better. Plots of $\Delta \mathrm{E}_{\mathrm{ad}}$ versus the previousone-hour average of $E_{\perp, \max } * N_{P S}$ are shown in Figures $4 h$, $5 \mathrm{~h}$, and $6 \mathrm{~h}$. The coefficients for the modified McIlwain electric field (Figure 4h) and the Weimer-96 electric field (Figure $5 \mathrm{~h}$ ) are similar to the instantaneous value coefficients. For the self-consistent electric field (Figure 6h), the coefficients are significantly less than those for Figure $6 \mathrm{~g}$. Because the particles take several hours to drift through the simulation domain, perhaps a longer integration time is needed. The final two panels of Figures 4-6 show the scatter plots for $\Delta \mathrm{E}_{\text {ad }}$ against the previous-two-hour average of $\mathrm{E}_{\perp, \max } * \mathrm{~N}_{\mathrm{PS}}$ and the previous-four-hour average of $E_{\perp, \max } * N_{P S}$, respectively. The correlation coefficients for all three electric field descriptions drop as the integration time is increased. Figures $4 i$ and $4 j$ are still significant numbers, but $R_{P}$ and $R_{S}$ for the other two field models are quite low. It is low because the electric field from 4 hours ago only marginally influences the present-time $\Delta \mathrm{E}_{\mathrm{ad}}$ (by delivering the $\mathrm{N}_{\mathrm{PS}}$ from 4 hours ago into the inner magnetosphere). In addition, after some time the relationship reverses (seen most 
clearly in Figures 4j, 5j, and $6 \mathrm{j}$ ), and the delivery of a large blob of plasma into the inner magnetosphere eventually causes a large net decrease in energy instead of a net increase.

\section{CONCLUSION}

This paper presented an analysis of the factors that parameterize the net adiabatic energy gain in the inner magnetosphere during magnetic storms. Adiabatic energization (deenergization) occurs when the plasma sheet particles move radially inward (outward) to form the stormtime ring current. A single storm was considered, that of April 17, 2002. This is an "average" storm, with a Dst minimum near $-100 \mathrm{nT}$, solar wind values that were not too large, and a modest duration for the main phase and recovery phase. Therefore, a generalization of these results to magnetic storms in general is possible but not robust.

It is concluded that the best parameter for quantifying the net adiabatic energy gain in the inner magnetosphere during storms is the instantaneous value of the product of the maximum westward electric field at the outer simulation boundary and the nightside near-Earth plasma sheet density. An average of this quantity's values over the previous hour yields a close second in the overall ranking of the correlation coefficients. However, all of the instantaneous magnetospheric quantities considered in this study produced large correlation coefficients. Therefore, they all could be considered useful predictors of $\Delta \mathrm{E}_{\mathrm{ad}}$. Long integration times over the parameters lessen the significance of the correlation.

Differences in the correlations were noted between the three potential electric field choices. The simplest field model, the modified McIlwain description, in general yielded the highest correlation coefficients for any given parameter (the average of the coefficients was 0.67). Even the time-integrated parameters produced statistically significant correlations. This field choice also produced the highest single correlation coefficient of 0.90 (Figure 4h). The Weimer-96 field model produced, in general, the lowest correlation coefficients for any given parameter (the average of the coefficients was 0.46). For this field there was a distinct break between the top two parameters (those mentioned in the previous paragraph) and the rest. The selfconsistent field produced the middle value, in general (the average of the coefficients was 0.53). The instantaneous electric field parameters (magnetospheric and solar wind) were quite good at quantifying $\Delta \mathrm{E}_{\mathrm{ad}}$ for this field choice. However, it also produced the two lowest correlation coefficients of the analysis (Figure 6j), and its time-integrated parameters were the lowest of the three field choices. Finally, all three electric field choices had poor correlation coefficients when $\Delta \mathrm{E}_{\mathrm{ad}}$ was compared against $\mathrm{P}_{\mathrm{dyn}, \mathrm{sw}}$.
As a final note, the reader is reminded of the complexity in Figure 1, and that many of the processes listed there were not considered in this study. The flow of energy through the inner magnetosphere is a nontrivial issue, with many factors contributing to and modifying the details. Furthermore, each magnetic storm is different, with the various processes waxing and waning in importance for numerous reasons. This study considered only the primary driving parameters of the net adiabatic energy gain of the stormtime ring current ions. It is believed that this is a rather general result with widespread applicability. However, much work still needs to be done to fully understand the factors influencing the development and dynamics of the inner magnetospheric hot plasma during magnetic storms.

Acknowledgments. The authors thank the organizers of the Huntsville 2002 Workshop for inviting G.V.K. to speak at the meeting. The authors would like to thank the sources of funding for this study: NASA grants NAG5-10297 and NAG-10850 and NSF grant ATM-0090165. The authors would also like to thank all of their data providers who made the ring current simulations possible, especially M. F. Thomsen and G. D. Reeves at the Los Alamos National Laboratory for the DANL data and CDAWeb for allowing access to the plasma and magnetic field data of the ACE spacecraft.

\section{REFERENCES}

Akasofu, S.-I., and S. Chapman, The ring current, geomagnetic disturbance and the Van Allen radiation belts, J. Geophys. Res., 66, 1321, 1961.

Alfvén, H., and C.-G. Fälthammar, Cosmical Electrodynamics, Oxford University Press, London, 1963.

Amm, O., Comment on "A three-dimensional, iterative mapping procedure for the implementation of an ionosphere-magnetosphere anisotropic Ohm's law boundary condition in global magnetohydrodynamic simulations" by Michael L. Goodman, Ann. Geophys., 14, 773, 1996.

Borovsky, J. E., M. F. Thomsen, and R. C. Elphic, The driving of the plasma sheet by the solar wind, J. Geophys. Res., 103, 17,617, 1998.

Burton, R. K., R. L. McPherron, and C. T. Russell, An empirical relationship between interplanetary conditions and Dst, J. Geophys. Res., 80, 4204, 1975.

Carovillano, R. L., and G. L. Siscoe, Energy and momentum theorems in magnetospheric processes, Rev. Geophys. Space Phys., 11, 289, 1973.

Carpenter, D. L., Whistler evidence of a "knee" in the magnetospheric ionization density profile, J. Geophys. Res., 68, 1675, 1963.

Chappell, C. R., T. E. Moore, and J. H. Waite, Jr., The ionosphere as a fully adequate source of plasma for the Earth's ionosphere, J. Geophys. Res., 92, 5896, 1987.

Chen, M. W., M. Schulz, L. R. Lyons, and D. J. Gorney, Stormtime 
transport of ring current and radiation belt ions, J. Geophys. Res., 98, 3835, 1993.

Church, S. R., and R. M. Throne, On the origin of plasmaspheric hiss: Ray path integrated amplification, J. Geophys. Res., 88, 7941, 1983.

Dessler, A. J., and E. N. Parker, Hydromagnetic theory of geomagnetic storms, J. Geophys. Res., 64, 2239, 1959.

Dungey, J. W., Interplanetary magnetic field and the auroral zones, Phys. Rev. Lett., 6, 47, 1961.

Dungey, J. W., The loss of Van Allen electrons due to whistlers, Planet. Space Sci., 11, 591, 1963.

Fenrich, F. R., and J. G. Luhmann, Geomagnetic response to magnetic clouds of different polarity, Geophys. Res. Lett., 25, 2999, 1998.

Fok, M-C., J. U. Kozyra, A. F. Nagy, C. E. Rasmussen, and G. V. Khazanov, A decay model of equatorial ring current and the associated aeronomical consequences, J. Geophys. Res., 98, 19,381, 1993

Fok, M.-C., T. E. Moore, and D. C. Delcourt, Modeling of inner plasma sheet and ring current during substorms, J. Geophys. Res., 104, 14,557, 1999.

Fok, M.-C., R. A. Wolf, R. W. Spiro, and T. E. Moore, Comprehensive computational model of the earth's ring current, J. Geophys. Res., 106, 8417, 2001.

Fok, M.-C., et al., Global ENA image simulations, Space Sci. Rev., 109, 77, 2003

Foster, J. C., P. J. Erickson, A. J. Coster, J. Goldstein, and F. J. Rich, Ionospheric signatures of plasmaspheric tails, Geophys. Res. Lett., 29(13), doi:10.1029/2002GL015067, 2002.

Galand, M. and A. D. Richmond, Ionospheric electrical conductances produced by auroral proton precipitation, J. Geophys. Res., 106, 117, 2001.

Gonzalez, W. D., J. A. Joselyn, Y. Kamide, H. W. Kroehl, G. Rostoker, B. T. Tsurutani, and V. M. Vasyliunas, What is a geomagnetic storm?, J. Geophys. Res., 99, 5771, 1994.

Goodman, M. L., A three-dimensional, iterative mapping procedure for the implementation of an ionosphere-magnetosphere anisotropic Ohm's law boundary condition in global magnetohydrodynamic simulations, Ann. Geophys., 13, 843, 1995.

Green, J. C., and M. G. Kivelson, A tale of two theories: How the adiabatic response and ULF waves affect relativistic electrons, J. Geophys. Res., 106, 25,777, 2001.

Hudson, M. K., V. A. Marchenko, I. Roth, M. Temerin, J. B. Blake, and M. S. Gussenhoven, Radiation belt formation during storm sudden commencements and loss during main phase, $A d v$. Space Res., 21 (4), 597-607, 1998.

Hultqvist, B. W., W. Riedler, and H. Borg, Ring current protons in the upper atmosphere within the plasmasphere, Planet. Space Sci., 24, 783, 1976.

Iijima, T., and T. A. Potemra, The amplitude distribution of fieldaligned currents at northern latitudes observed by TRIAD, $J$. Geophys. Res., 81, 2165, 1976.

Jaggi, R. K., and R. A. Wolf, Self-consistent calculation of the motion of a sheet of ions in the magnetosphere, J. Geophys. Res., 78, 2852, 1973.
Jordanova, V. K., L. M. Kistler, J. U. Kozyra, G. V. Khazanov, and A. F. Nagy, Collisional losses of ring current ions, J. Geophys. Res., 101, 111, 1996.

Jordanova, V. K., J. U. Kozyra, A. F. Nagy, and G. V. Khazanov, Kinetic model of the ring current-atmosphere interactions, $J$. Geophys. Res., 102, 14,279, 1997.

Jordanova, V. K., L. M. Kistler, C. J. Farrugia, and R. B. Torbert, Effects of inner magnetospheric convection on ring current dynamics: March 10-12, 1998, J. Geophys. Res., 106, 29,705, 2001.

Kennel, C. F., and H. E. Petschek, Limit on stably trapped particle fluxes, J. Geophys. Res., 71, 1, 1966.

Khazanov, G. V., and M. W. Liemohn, Nonsteady state ionosphereplasmasphere coupling of superthermal electrons, J. Geophys. Res., 100, 9669, 1995.

Khazanov, G. V., and M. W. Liemohn, Kinetic theory of superthermal electron transport, in Recent Research Developments in Geophysics, vol. 3 (part 2), edited by S. G. Pandalai, pp. 181201, Research Signpost, Trivandrum, India, 2000.

Khazanov, G. V., and M. W. Liemohn, Transport of photoelectrons in the nightside magnetosphere, J. Geophys. Res., 107(A5), 1064, doi: 10.1029/2001JA000163, 2002.

Khazanov, G. V., T. E. Moore, M. W. Liemohn, V. K. Jordanova, and M.-C. Fok, Global collisional model of high-energy photoelectrons, Geophys. Res. Lett., 23, 331, 1996a.

Khazanov, G. V., T. E. Moore, E. N. Krivorutsky, J. L. Horwitz, and M. W. Liemohn, Lower hybrid turbulence and ponderomotive force effects in space plasmas subjected to large-amplitude low-frequency waves, Geophys. Res. Lett., 23, 797, 1996b.

Khazanov, G. V., E. N. Krivorutsky, T. E. Moore, M. W. Liemohn, and J. L. Horwitz, Lower hybrid oscillations in multicomponent space plasmas subjected to ion cyclotron waves, J. Geophys. Res., 102, 175, 1997.

Khazanov, G. V., M. W. Liemohn, J. U. Kozyra, and T. E. Moore, Inner magnetospheric superthermal electron transport: Photoelectron and plasma sheet electron sources, J. Geophys. Res., 103, 23,485, 1998.

Khazanov, G. V., K. V. Gamayunov, and M. W. Liemohn, Alfvén waves as a source of lower hybrid activity in the ring current region, J. Geophys. Res., 105, 5403, 2000a

Khazanov, G. V., M. W. Liemohn, J. U. Kozyra, and D. L. Gallagher, Global energy deposition to the topside ionosphere from superthermal electrons, J. Atmos. Solar-Terr. Physics, 62, 947, 2000b.

Khazanov, G. V., K. V. Gamayunov, V. K. Jordanova, and E. $\mathrm{N}$. Krivorutsky, A self-consistent model of the interacting ring current ions and electromagnetic ion cyclotron waves, initial results: Waves and precipitating fluxes, J. Geophys. Res., 107 (A6), 1085, doi: 10.1029/2001JA000180, 2002.

Khazanov, G. V., M. W. Liemohn, T. S. Newman, M.-C. Fok, and R. W. Spiro, Self-consistent magnetosphere-ionosphere coupling: Theoretical studies, J. Geophys. Res., 108(A3), 1122, doi:10.1029/2002JA009624, 2003a.

Khazanov, G.V., K. V. Gamayunov, V. K. Jordanova, Self-consistent model of magnetospheric ring current and electromagnetic 
ion cyclotron waves: The May2-7, 1998, storm, J. Geophys. Res., 108(A12), 1419, doi: 10.1029/ 2003JA009833, 2003 b.

Khazanov, G. V., M. W. Liemohn, T. S. Newman, M.-C. Fok, and A. J. Ridley, Magnetospheric convection electric field dynamics and stormtime particle energization: Case study of the magnetic storm of 4 May 1998, Ann Geophys., 22, 497, 2004a.

Khazanov, G. V., M. W. Liemohn, M.-C. Fok, T. S. Newman, and A. J. Ridley, Stormtime particle energization with AMIE potentials, J. Geophys. Res., 109, A05209, doi: 10.1029/ 2003JA010186, 2004b.

Kozyra, J. U., and M. W. Liemohn, Ring current energy input and decay, Space Sci. Rev, 109, 105, 2003.

Kozyra, J. U., C. E. Rasmussen, R. H. Miller, and E. Villalon, Interaction of ring current and radiation belt protons with ducted plasmaspheric hiss, 2, Time evolution of the distribution function, J. Geophys. Res., 100, 21,911, 1995.

Kozyra, J. U., A. F. Nagy, and D. W. Slater, High-altitude energy source(s) for stable auroral red arcs, Rev. Geophys., 35, 155190, 1997.

Kozyra, J. U., M. W. Liemohn, C. R. Clauer, A. J. Ridley, M. F. Thomsen, J. E. Borovsky, J. L. Roeder, and V. K. Jordanova, Two-step Dst development and ring current composition changes during the 4-6 June 1991 magnetic storm, J. Geophys. Res., 107(A8), doi: 10.1029/2001JA000023, 2002.

Lee, L. C., J. R. Kan, and S.-I. Akasofu, Ring current energy injection rate and solar wind-magnetosphere energy coupling, Planet. Space Sci., 30, 627, 1982.

Lemaire, J. F., and K. I. Gringauz, The Earth's Plasmasphere, Cambridge University Press, New York, 1998.

Liemohn, H. B., Cyclotron-resonance amplification of VLF and ULF whistlers, J. Geophys. Res., 72, 39, 1967.

Liemohn, M. W., Yet another caveat to the Dessler-Parker-Sckopke relation, J. Geophys. Res., 108(A6), 1251, doi: 10.1029/ 2003JA009839, 2003.

Liemohn, M. W., and J. U. Kozyra, Assessing the importance of convective and inductive electric fields in forming the stormtime ring current, in Sixth International Conference on Substorms, edited by R. M. Winglee, Univ. Washington, Seattle, p.456, 2002.

Liemohn, M. W., G. V. Khazanov, and J. U. Kozyra, Guided plasmaspheric hiss interactions with superthermal electrons, 1 , Resonance curves and timescales, J. Geophys. Res., 102, $11,619,1997$.

Liemohn, M. W., G. V. Khazanov, and J. U. Kozyra, Banded electron structure formation in the inner magnetosphere, Geophys. Res. Lett., 25, 877, 1998.

Liemohn, M. W., G. V. Khazanov, P. D. Craven, and J. U. Kozyra, Nonlinear kinetic modeling of early stage plasmaspheric refilling, J. Geophys. Res., 104, 10,295, 1999.

Liemohn, M. W., J. U. Kozyra, P. G. Richards, G. V. Khazanov, M. J. Buonsanto, and V. K. Jordanova, Ring current heating of the thermal electrons at solar maximum, J. Geophys. Res., 105, $27,767,2000$

Liemohn, M. W., J. U. Kozyra, M. F. Thomsen, J. L. Roeder, G. Lu, J. E. Borovsky, and T. E. Cayton, Dominant role of the asymmetric ring current in producing the stormtime Dst*, $J$. Geophys. Res., 106, 10,883, 2001a.

Liemohn, M. W., J. U. Kozyra, C. R. Clauer, and A. J. Ridley, Computational analysis of the near-Earth magnetospheric current system, J. Geophys. Res., 106, 29,531, 2001 b.

Liemohn, M. W., J. U. Kozyra, C. R. Clauer, G. V. Khazanov, and M. F. Thomsen, Adiabatic energization in the ring current and its relation to other source and loss terms, J. Geophys. Res., 107(A4), 1045, doi: 10.1029/2001JA000243, 2002.

Liemohn, M. W., A. J. Ridley, D. L. Gallagher, D. M. Ober, and J. U. Kozyra, Dependence of plasmaspheric morphology on the electric field description during the recovery phase of the April 17, 2002 magnetic storm, J. Geophys. Res., 109, A03209, doi: 10.1029/2003JA010304, 2004.

Lyons, L. R., and D. J. Williams, A source for the geomagnetic storm main phase ring current, J. Geophys. Res., 85, 523, 1980.

McIlwain, C. E., A Kp dependent equatorial electric field model, Adv. Space Res., 6(3), 187, 1986.

McPherron, R. L., The role of substorms in the generation of magnetic storms, in Magnetic Storms, Geophys. Monogr. Ser., 98, edited by B. T. Tsurutani, W. D. Gonzalez, Y. Kamide and J. K. Arballo, p. 131, AGU, Washington, D. C., 1997.

O'Brien, T. P., and R. L. McPherron, An empirical phase space analysis of ring current dynamics: Solar wind control of injection and decay, J. Geophys. Res., 105, 7707, 2000a.

O'Brien, T. P. and R. L. McPherron, Evidence against an independent solar wind density driver of the terrestrial ring current, Geophys. Res. Lett., 27, 3797, 2000b.

Ober, D. M., J. L. Horwitz, and D. L. Gallagher, Formation of density troughs embedded in the outer plasmasphere by subauroral ion drift events, J. Geophys. Res. 102, 14,595, 1997.

Parker, E. N., and H. A. Stewart, Nonlinear inflation of a magnetic dipole, J. Geophys. Res., 72, 5287, 1967.

Rairden, R. L., L. A. Frank, and J. D. Craven, Geocoronal imaging with Dynamics Explorer, J. Geophys. Res., 91, 13,613, 1986.

Rasmussen, C. E., S. M. Guiter, and S. G. Thomas, Two-dimensional model of the plasmasphere: refilling time constants, Planet. Space Sci., 41, 35-42, 1993.

Ridley, A. J., and M. W. Liemohn, A model-derived description of the penetration electric field, J. Geophys. Res., 107(A8), 1151, doi: 10.1029/2001JA000051, 2002.

Ridley, A. J., D. L. De Zeeuw, T. I. Gombosi, and K. G. Powell, Using steady-state MHD results to predict the global state of the magnetosphere-ionosphere system, J. Geophys. Res., 106, 30,067, 2001.

Ridley, A. J., T. I. Gombosi, and D. L. De Zeeuw, Ionospheric control of the magnetosphere: Conductance, Ann. Geophys., 22, 567, 2004.

Roederer, J. G., Dynamics of Geomagnetically Trapped Radiation, Springer-Verlag, New York, 1970.

Rostoker, G., E. Friedrich, and M. Dobbs, Physics of magnetic storms, in Magnetic Storms, Geophys. Monogr. Ser., 98, edited by B. T. Tsurutani, W. D. Gonzalez, Y. Kamide and J. K. Arballo, p. 149, AGU, Washington, D. C., 1997. 
Siscoe, G. L., A unified treatment of magnetospheric dynamics, Planet. Space Sci., 14, 947, 1966.

Sckopke, N., A general relation between the energy of trapped particles and the disturbance field near the Earth, J. Geophys. Res., 71, 3125, 1966.

Smith, J. P., M. F. Thomsen, J. E. Borovsky, and M. Collier, Solar wind density as a driver for the ring current in mild storms, Geophys. Res. Lett., 26, 1797-800, 1999.

Sugiura, M., and S. Chapman, The average morphology of geomagnetic storms with sudden commencement, Abh. Akad. Wiss. Göttingen. Math. Phys. Kl., 4, 1-53, 1960.

Summers, D., and R. M. Thorne, Relativistic electron pitch-angle scattering by electromagnetic ion cyclotron waves during geomagnetic storms, J. Geophys. Res., 108(A4), 1143, doi: 10.1029/ 2002JA009489, 2003.

Takahashi, T., Energy degradation and transport of photoelectrons escaping from the upper ionosphere. Rept. Ionos. and Space Res. Jap., 27, No.1, 79, 1973.

Takahashi, S., T. Iyemori, and M. Takeda, A simulation of the storm-time ring current, Planet. Space Sci., 38, 1133-1141, 1990.

Tsurutani, B. T., and W. D. Gonzalez, The interplanetary causes of magnetic storms: A review, in Magnetic Storms, Geophys. Monogr. Ser., 98, edited by B. T. Tsurutani, W. D. Gonzalez, Y. Kamide and J. K. Arballo, p. 77, AGU, Washington, D. C., 1997.

Tsyganenko, N. A., A model of the near magnetosphere with a dawn-dusk asymmetry: 2 . Parameterization and fitting to observations, J. Geophys. Res., 107(A8), 1176, doi: 10.1029/ 2001JA000220, 2002
Weimer, D. R., A flexible, IMF dependent model of high-latitude electric potentials having "space weather" applications, Geophys. Res. Lett., 23, 2549, 1996.

Wolf, R. A., Magnetospheric configuration, in Introduction to Space Physics, edited by M. G. Kivelson and C. T. Russell, p. 288, Cambridge University Press, New York, 1995.

Wolf, R. A., et al., Computer simulations of inner magnetospheric dynamics for the magnetic storm of July 29, 1977, J. Geophys. Res., 87, 5949, 1982.

Wolf, R. A., J. W. Freeman, Jr., B. A. Hausman, R. W. Spiro, R. V. Hilmer, and R. L. Lambour, Modeling convection effects in magnetic storms, in Magnetic Storms, Geophys. Monogr. Ser., 98, edited by B. T. Tsurutani, W. D. Gonzalez, Y. Kamide, and J. K. Arballo, American Geophysical Union, p. 161, 1997.

Yeh, H.-C., J. C. Foster, F. J. Rich, and W. Swider, Storm time electric field penetration observed at midlatitude, J. Geophys. Res., 96, 5707, 1991.

Young, D. T., H. Balsiger, and J. Geiss, Correlations of magnetospheric ion composition with geomagnetic and solar activity, $J$. Geophys. Res., 87, 9077, 1982.

G. V. Khazanov, National Space Science and Technology Center, NASA Marshall Space Flight Center, Huntsville, Alabama 35899. (george.v.khazanov@nasa.gov)

M. W. Liemohn, Atmospheric, Oceanic, and Space Sciences Department, University of Michigan, 2455 Hayward St., Ann Arbor, Michigan 48109-2143. (liemohn@umich.edu) 

LIEMOHN AND KHAZANOV 17 